\title{
A Field Experiment on Directed Giving at a Public University*
}

\author{
Catherine C. Eckel \\ Department of Economics, \\ Texas A\&M University \\ Jonathan Meer \\ Department of Economics, \\ Texas A\&M University and NBER \\ David H. Herberich ${ }^{\dagger}$ \\ Marqeta, Inc.
}

December 28, 2015

\begin{abstract}
The use of directed giving - allowing donors to target their gifts to specific organizations or functions - is pervasive in fundraising, yet little is known about its effectiveness. We conduct a field experiment at a public university in which prospective donors are presented with either an opportunity to donate to the unrestricted Annual Fund, or an opportunity of donating to the Annual Fund and directing some or all of their donation towards the academic college from which they graduated. While there is no effect on the probability of giving, donations are significantly larger when there is the option of directing. However, the value of the option does not come directly from use, as very few donors choose to direct their gift.
\end{abstract}

${ }^{*}$ We are grateful to the Association of Former Students at Texas A\&M University for their cooperation, particularly Chanee Carlson, Larry Cooper, and Marty Holmes. Wei Zhan provided excellent research assistance. We gratefully acknowledge financial support from the National Science Foundation through grant number SES-1338680. Inc.

$\dagger$ The views presented here are solely those of the authors and do not represent those of Marqeta,

†Corresponding Author. jmeer@econmail.tamu.edu

(C) 2016. This manuscript version is made available under the Elsevier user license http://www.elsevier.com/open-access/userlicense/1.0/ 


\section{Introduction}

The use of directed giving - allowing donors to target their gifts to specific organizations or functions - is pervasive in fundraising. As early as 1994, United Way responded to a drop in contribution levels by introducing donor choice, for the first time allowing donors to select the organization to receive their donation (Barman, 2002). Targeting proved popular, and grew to $18.4 \%$ of donations by 1999 . United Way's 2012 annual report notes that $47 \%$ of assets are unrestricted, reflecting the overall pattern of giving nationwide. ${ }^{1}$ However, surprisingly little is known about its effectiveness for increasing donations, nor the potential costs and other ramifications. In particular, if a large proportion of giving is restricted in its use, charities' flexibility in allocating their resources would be reduced. ${ }^{2}$

While directed giving clearly plays an important role in fundraising, there are no previous controlled studies designed to directly assess its impact in the field. We conduct a field experiment in conjunction with the Association of Former Students (AFS) at Texas A\&M University in which prospective donors can either donate to the Annual Fund (the standard way in which AFS raises money), or have the option of directing some or all of their gift to an Academic Fund benefiting the academic college housing the department from which they graduated. We randomly assign former students to one of these two treatments and find no effect on the probability of giving, yet much larger donations from those who did give. Surprisingly, very few donors choose to direct any part of their gift. Altogether, our results suggest that donors who would have given regardless respond to being offered a choice by

\footnotetext{
${ }^{1}$ The United Way national organization does not report donations by restricted status. The regional organizations vary considerably, but average around half of giving as unrestricted.

${ }^{2}$ One recent news report argued that "directed giving will sting" nonprofits (Bailey, 2010) by restricting the ability of umbrella organizations to allocate funds. Another noted that despite exceeding its 2014 fundraising goal, a regional United Way organization had seen a twentyfold increase in directed gifts and that the restrictions inherent in this trend would be "much harder on smaller agencies that don't have the benefit of marketing or communication staffs." (Lippmann, 2015) No less an authority than the online humor magazine Cracked discussed this problem in an article entitled "5 Popular Forms of Charity (That Aren't Helping)," giving a number of examples in which earmarked donations caused a "massive imbalance in funding that [led] to some serious bureaucratic absurdities." (Hill, 2012)
} 
giving more, but do not take up the option; at least in our context, concerns about earmarking are unfounded.

Several experimental studies explore topics related to directed giving. Li et al. (2013) provide the first lab-experimental evidence (to our knowledge) measuring the impact of targeted giving. In a "real charity" lab experiment, where subjects make donations from their earnings to charitable organizations, they show that targeting has a positive impact on donations. The study compares directed giving to two specific causes - disaster relief and cancer research - with donations to the United Way general fund. A similar comparison is made for government organizations, with the "Gifts to the United States" fund, which feeds into federal revenue, as the general fund. They find that targeting specific causes more than doubles the likelihood of giving and the size of contributions, relative to the general funds. The impact of targeting is significantly greater for government organizations, most likely due to the broader portfolio of functions under the government umbrella.

Two additional types of experimental studies provide insight into the potential value of directed giving. Small and Loewenstein (2003) use lab and field experiments to explore the "identifiable victim" phenomenon: people will often give substantially more to an identifiable than a statistical victim. For example, in 1987, one child, "Baby Jessica," became a media sensation when she fell into a well near her home in Texas, and she received over $\$ 700,000$ in donations from the public. Small and Loewenstein find that a recipient who has already been selected from a list of possible targets receives larger donations that one who has not yet been selected from the list: the difference was $62 \%$ in a lab experiment and $26 \%$ in a field experiment. This suggests that allowing donors to target a specific victim may substantially increase giving. It is this impulse that is exploited in fundraising campaigns such as World Vision, Compassion International, or Children International, which ask donors to sponsor a specific child through regular donations. In a complementary paper in this special issue, Al-Ubaydli and Yeomans (n.d.) use a field experiment on volunteer tax preparers and their clients to examine the identifiability effect. They find that the volunteers are more likely to make an additional donation with a single recipient, but the clients are less likely to do so. Their study suggests that this effect is context- 
specific and perhaps more fragile than previously thought.

A second type of study examines "paternalistic" donor restrictions. For example, a donor might be willing to contribute more if they can control how a recipient is allowed to spend the money. Batista et al. (2014) report the result of lab-in-thefield experiments in Tanzania where the recipient is the closest person to the donor outside their family. They show that donors are willing to give about $14 \%$ more when they have the option to give goods rather than in cash. The magnitude of the effect is larger than other experimental manipulations such as the price of giving or the endowment to the donors. In a related study, Jones (2014) shows that even when such paternalistic restrictions are costly, about 60 percent of subjects are willing to pay to restrict the use of a donation so that it cannot be spent on cigarettes, alcohol or drugs. These studies illustrate the responsiveness of giving when donors have the ability to target the use of the funds.

One charitable giving study outside of the directed giving space provides evidence on increased donor agency leading to increased donations, even when those donors do not act upon their option. Kamdar et al. (2013) present the results of a large scale field experiment that included a "once and done" treatment in a charitable giving campaign conducted through the mail. The "once and done" treatment offers perspective donors the option of never being contacted again by the charity, if they donate. This treatment leads to almost twice as many donations and a ten percent increase in the average gift amount. However, the decision to not be contacted again was only utilized by $38 \%$ of the donors leading Kamdar et al. (2013) to suggest reciprocity as the main underlying cause of the increase in donations. This result is in line with our findings, and both studies suggest a large potential impact on charitable giving by increasing agency of the donor. The result of increased donations without the action being taken is especially important for directed giving in which restricting funds is of primary concern. 


\section{Experimental Design}

In order to isolate the impact of directed giving, we designed a natural field experiment centered around creating exogenous variation in the option to direct a donor's gift. The experimental design consisted of two subject groups: standard (Annual Fund Only) and directed (Annual or Academic Funds). Both groups received an e-mail describing the values of Texas A\&M University and asking for support in the form of a donation. The e-mails received are identical, including the subject line, with one exception: the directed group was also provided an option of directing a gift to the donor's academic college. The control group did not receive any option, as is standard for the AFS Annual Fund. All other aspects of the request for a donation were the same as AFS's normal solicitations.

Subjects were contacted via nearly identical e-mails, with the only difference in solicitation consisting of one additional sentence for the directed group. For the control group, the e-mail appeal only gave the Annual Fund as the possible recipient: "Your gift to The Association of Former Students' Annual Fund supports scholarships, academic excellence, and student organizations across the university." The e-mail to the directed group included a sentence presenting an option of directing a donation (addition in italics): "Your gift to The Association of Former Students' Annual Fund supports scholarships, academic excellence, and student organizations across the university. You can also choose to direct some or all of your gift specifically to support programs at your academic college."

Each e-mail contained a hyperlink to a web page for the donor to make a donation. Two web pages were designed, one for each group, in order to provide the directed group an entry option for donations to the academic college from which the donor graduated. The option to donate to the academic college was in addition to the standard entry option for the Annual Fund which was included in both the directed and control web pages. ${ }^{3}$

\footnotetext{
${ }^{3}$ The full e-mails for the control and directed groups, as well as the web pages used to facilitate donations, can be found in the Appendix. Due to adjustments by AFS staff, there are some minor differences in the layout of the web pages; it seems unlikely, however, that these differences would drive our pattern of results.
} 
The control and directed groups were created from a list of donors that had given in 2012, but had not yet given in 2013. Subjects were randomly assigned, stratifying the sample on college, year of graduation and gender, into two groups, with 5,303 control recipients and 5,302 directed recipients. Table 1 shows p-values for balance between the two samples; it is clear that the randomization was successful. The two lists of potential donors were provided to the AFS to administer the appeal. The AFS handled the lists separately to ensure the correct e-mail body was sent but otherwise the appeal operated in the standard fashion. ${ }^{4}$

The first round of e-mails was sent on December 19, 2013. A second e-mail for non-respondents was sent on December 27, 2013. Donations were received through the two websites administered by the AFS. ${ }^{5}$ Donations stopped being recorded for our data on December 31, 2013. The results which follow utilize all donations received by the control and directed groups during this time period. The randomization in the sample permits the interpretation that the experimental trigger caused donations through any channel.

\section{Results}

There is little difference in the probability of giving across the conditions; 442 donors $(8.3 \%)$ gave in the control (Annual Fund Only) treatment, while 454 donors $(8.6 \%)$ gave in the directed (Annual and Academic Funds) treatment. Figure 1 shows the distribution of donations, conditional on making a gift, by treatment; it is evident that there are somewhat fewer small gifts and somewhat more very large gifts when donors are given a choice. This is borne out by the comparison of means in Table 2 , in which we show that while there is no difference in the giving rate between the two treatments, the average gift is substantially larger in the choice condition. The unconditional average gift size is $\$ 7.61$ larger when donors can target their gift $(\mathrm{p}$

\footnotetext{
${ }^{4}$ Five subjects were mistakenly allocated to the incorrect group; we remove these individuals from the sample, leaving 5,300 subjects in each treatment. Including them does not affect the results.

${ }^{5}$ Nine gifts were received by mail; five from the control group and four from the treatment group.
} 
$=0.01)$. Since the giving rates do not differ, it is unsurprising that this pattern carries over to the gift size conditional on giving, which is $\$ 82.33$ larger in the choice condition. A Kruskal-Wallis test shows that the distributions of the two groups are different at $\mathrm{p}=0.092$.

Due to the presence of a number of large gifts in the choice condition, we examine the results after Winsorizing the gifts conditional on giving at $1 \%$ and $5 \%$. That is, we set the top $1 \%$ (or $5 \%$ ) of the conditional distribution of donations equal to the $99^{\text {th }}$ (or $95^{\text {th }}$ ) percentile; thus, the observations are still counted in the statistics but have a less-outsized influence. The results are unchanged: the differences for both $1 \%$ and 5\% Winsorizing are still statistically significant; we therefore conclude that our results are not entirely driven by outliers, though much of the impact of choice seems to be driven by a greater proportion of very large gifts.

Given that our experiment focuses on the effects of choice, we next turn to whether donors choose to direct their gifts when the choice is available. Strangely, despite clearly giving greater amounts in response to the availability of choice, few donors choose to actually utilize that choice. Only 11 donors in the choice condition made any gift to the Academic Fund, just 2.4\% of respondents. ${ }^{6}$ Among these 11 individuals, $56.0 \%$ of dollars were directed to the Academic Fund, with a median of $50 \%$; only two donors chose to direct the whole of their gift. These donors gave $\$ 209$ more than their non-directing counterparts in the choice condition, but the sample is so small that this difference is significant only at $\mathrm{p}=0.22$.

\section{Conclusion}

Our results suggest that the choice condition has no impact on the probability of making a gift, but a large impact on the amount given conditional on making a gift; that is, donors who were planning on giving regardless have a preference for being offered a choice. The increase in amount given leads to an increase in average gift size, consistent with prior studies concerning the "identifiable victim" phenomenon

\footnotetext{
${ }^{6}$ Two donors in the Annual Fund group asked to direct their gifts; one donor directed the entirety of the gift while the other directed one-third.
} 
and "paternalistic" donor restrictions: being able to identify the recipient or control spending increases gift size. However, donors do not, in general, avail themselves of the option to direct their gifts. This pattern runs counter to both identifiable victim and paternalistic motives. The former predicts that donors will give more when the beneficiary can be more clearly identified, directing their gifts to a more identifiable target when given the option to do so. The latter motive also implies that donors would choose to direct their gifts to causes they support rather than to a general fund. Thus our results suggest a novel component to directed giving that should be considered when presenting a choice of donation options: the offer of increased agency may increase donor gifts. A result in line with the findings of Kamdar et al. (2013).

Charities are often reluctant to implement directed giving because of the resulting restrictions on their use of funds. The results from our study should help alleviate this concern. In all, the Association of Former Students raised approximately $\$ 40,000$ more by allowing for choice than it would have otherwise, with only about $2 \%$ of the $\$ 148,914$ raised in the choice condition being restricted to the Academic Fund. In this case, allowing for choice increases donations without limiting charities' flexibility in allocating donations.

The potential for increasing fundraising by offering a directed choice is of obvious value if it does not lead to unmanageable restrictions on the funds. Future research will be needed to further understand the situations in which donors react positively to the option to direct, but without overly restricting the organization's flexibility. In addition, future work should test the impact of permitting a wider set of choices, including short or long menus that do or do not include the unrestricted Annual Fund as an option. This will allow further investigation of the hypothesized "paradox of choice" in the context of charitable giving, and a more careful assessment of the extent to which donors value the availability of choice alone. 


\section{References}

Al-Ubaydli, Omar and Michael Yeomans, "Do People Donate More When They Perceive a Single Beneficiary Whom They Know? A Field Experimental Test of the Identifiability Effect," Journal of Behavioral and Experimental Economics.

Bailey, Thomas, "Directed Giving Will Sting Shelby County Nonprofit Groups," Aug 28, 2010. www.commercialappeal.com, http://www.commercialappeal.com/ business/directed-giving-will-sting. Online article; accessed April 05, 2015.

Barman, Emily A., "Asserting Difference: The Strategic Response of Nonprofit Organizations to Competition," Social Forces, 2002, 80 (4), 1191-1222.

Batista, Catia, Dan Silverman, and Dean Yang, "Directed Giving: Evidence from an Inter-Household Transfer Experiment," 2014. IZA Working Paper.

Hill, Mark, "5 Popular Forms of Charity (That Aren't Helping)," July 01, 2012. www.cracked.com, http://www.cracked.com/article_19899_ 5-popular-forms-charity-that-arent-helping_p2.html. Online article; accessed April 12, 2014.

Jones, Kristy, "Stereotypes in Giving: Altruism, Paternalism and Ethnicity," 2014. Unpublished manuscript, Monash University.

Kamdar, Amee, Steven D Levitt, John A.List, Brian Mullaney, and Chad Syverson, "Once and Done: Leveraging Behavioral Economics to Increase Charitable Contributions," 2013. SPI Working Paper Series.

Li, Sherry Xin, Catherine Eckel, Philip J. Grossman, and Tara Larson, "Who's in Charge? Donor Targeting Enhances Voluntary Giving to Government," 2013. Working paper, Texas A \&M University.

Lippmann, Rachel, "More Directed Giving, Some Responding To Ferguson, Leaves Less For Other United Way Agencies," Jan 11, 2015. http://news.stlpublicradio.org, http://news.stlpublicradio.org/post/ more-directed-giving-some-responding-ferguson-leaves-less-other-united-way-agencies. Online article; accessed April 05, 2015.

Small, Deborah A. and George Loewenstein, "Helping a Victim or Helping the Victim: Altruism and Identifiability," Journal of Risk and Uncertainty, 2003, $26(1), 5-16$. 


\section{$5 \quad$ Tables and Figures}

- Control (Annual Fund Only) — Directed (Annual and Academic Funds)

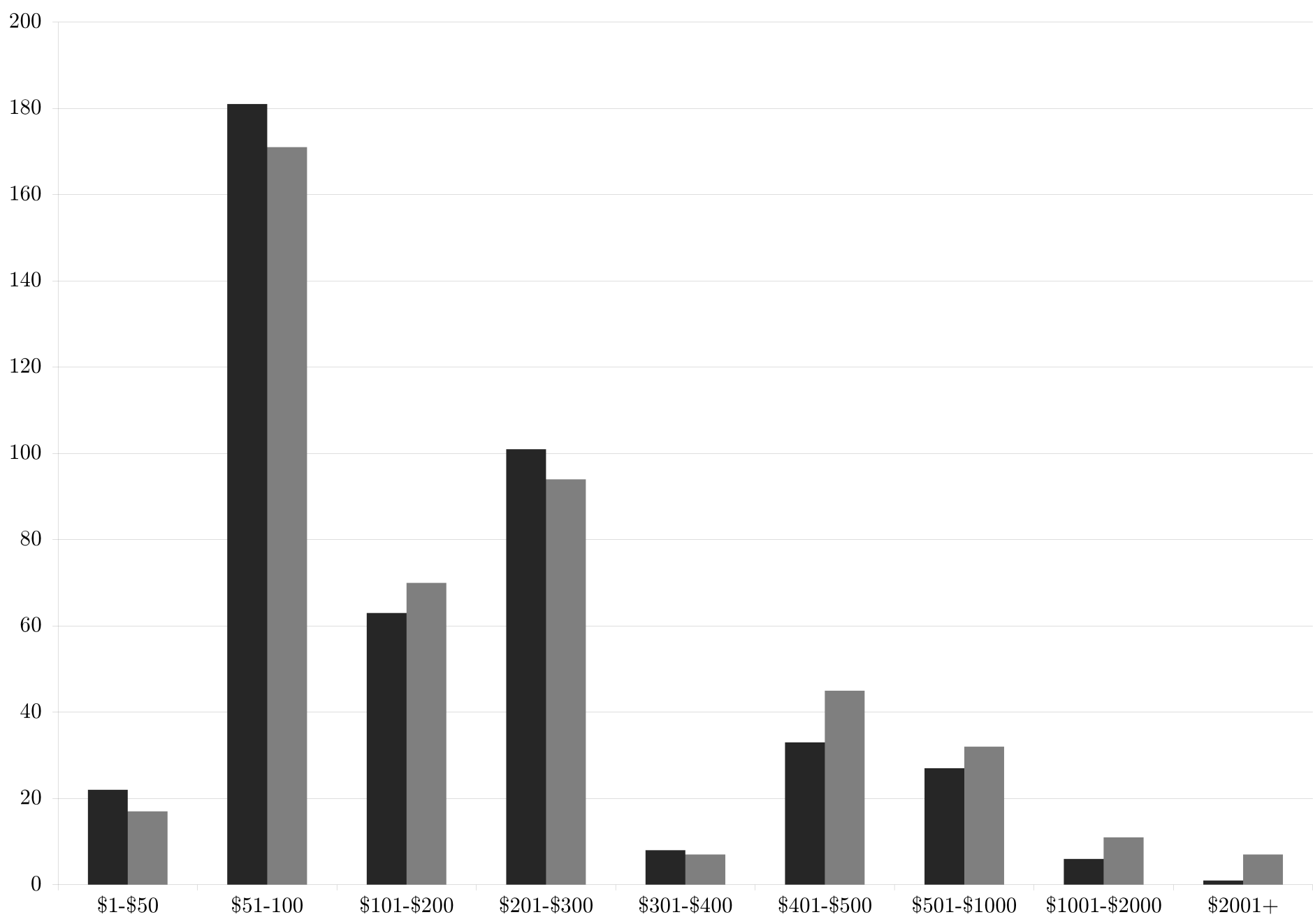

Figure 1: Number of Gifts by Size, Conditional on Giving 
Table 1: Summary Statistics

\begin{tabular}{|c|c|c|c|}
\hline & $\begin{array}{c}\text { Control } \\
\text { Annual Fund Only }\end{array}$ & $\begin{array}{c}\text { Directed } \\
\text { Annual and Academic Funds }\end{array}$ & $\begin{array}{l}\text { Difference } \\
\text { p-value }\end{array}$ \\
\hline Male & $\begin{array}{c}0.625 \\
(0.484)\end{array}$ & $\begin{array}{c}0.625 \\
(0.484)\end{array}$ & 1.000 \\
\hline Numbers of years since graduation & $\begin{array}{c}22.03 \\
(13.43)\end{array}$ & $\begin{array}{c}22.01 \\
(13.42)\end{array}$ & 0.950 \\
\hline Texas & $\begin{array}{c}0.816 \\
(0.387)\end{array}$ & $\begin{array}{c}0.815 \\
(0.388)\end{array}$ & 0.873 \\
\hline \multicolumn{4}{|l|}{ College } \\
\hline Agriculture \& Life Sciences & $\begin{array}{c}0.185 \\
(0.388)\end{array}$ & $\begin{array}{c}0.184 \\
(0.388)\end{array}$ & 0.980 \\
\hline Architecture & $\begin{array}{c}0.046 \\
(0.21)\end{array}$ & $\begin{array}{c}0.047 \\
(0.211)\end{array}$ & 0.963 \\
\hline Business Administration & $\begin{array}{c}0.189 \\
(0.392)\end{array}$ & $\begin{array}{c}0.189 \\
(0.392)\end{array}$ & 0.980 \\
\hline Education & $\begin{array}{c}0.092 \\
(0.289)\end{array}$ & $\begin{array}{c}0.092 \\
(0.289)\end{array}$ & 1.000 \\
\hline Engineering & $\begin{array}{l}0.244 \\
(0.43)\end{array}$ & $\begin{array}{l}0.244 \\
(0.43)\end{array}$ & 1.000 \\
\hline Bush School & $\begin{array}{c}0.001 \\
(0.027)\end{array}$ & $\begin{array}{c}0.001 \\
(0.034)\end{array}$ & 0.527 \\
\hline Geosciences & $\begin{array}{c}0.018 \\
(0.134)\end{array}$ & $\begin{array}{c}0.018 \\
(0.133)\end{array}$ & 0.942 \\
\hline Liberal Arts & $\begin{array}{c}0.144 \\
(0.351)\end{array}$ & $\begin{array}{c}0.144 \\
(0.351)\end{array}$ & 0.978 \\
\hline Science & $\begin{array}{c}0.043 \\
(0.202)\end{array}$ & $\begin{array}{c}0.043 \\
(0.202)\end{array}$ & 0.962 \\
\hline Veterinary Medicine & $\begin{array}{c}0.038 \\
(0.191) \\
\end{array}$ & $\begin{array}{c}0.038 \\
(0.191) \\
\end{array}$ & 1.000 \\
\hline Observation & 5300 & 5300 & 10600 \\
\hline
\end{tabular}

Note 1: Mean and standard deviations (in parentheses) in Column 1 and 2.

Note 2: p-values for difference-in-means in Column $3 \quad 10$ 
Table 2: Results

\begin{tabular}{lccc}
\hline \hline & $\begin{array}{c}\text { Control } \\
\text { Annual Fund Only }\end{array}$ & $\begin{array}{c}\text { Directed } \\
\text { Annual } \\
\text { and Academic Funds }\end{array}$ & Difference \\
\hline Unconditional on Giving & & & \\
Giving rate & 0.083 & 0.086 & -0.002 \\
& $(0.277)$ & $(0.280)$ & $(0.005)$ \\
Dollars given & 20.49 & 28.10 & $-7.61^{* * *}$ \\
& $(107.33)$ & $(186.00)$ & $(2.95)$ \\
\hline Observations & 5300 & 5300 & 10600 \\
\hline Conditional on Giving & & & \\
Dollars given & 245.67 & 328.01 & $-82.33^{* * *}$ \\
& $(288.06)$ & $(553.25)$ & $(29.59)$ \\
Winsorized (1\%) & 243.41 & 300.58 & $-57.17^{* * *}$ \\
& $(269.72)$ & $(377.89)$ & $(21.99)$ \\
Winsorized (5\%) & 233.90 & 269.21 & $-35.32^{* *}$ \\
& $(222.71)$ & $(260.24)$ & $(16.20)$ \\
\hline Observations & 442 & 454 & 896 \\
\hline \hline
\end{tabular}

Note 1: Mean and Standard deviations (in parentheses) in Column 1 and 2

Note 2: Difference and standard errors (in parentheses) in Column 3. ${ }^{*} p<0.05,{ }^{* *} p<0.01,{ }^{* * *} p<0.001$ 


\section{Appendix: Body of E-mails}

(a) Control E-mail

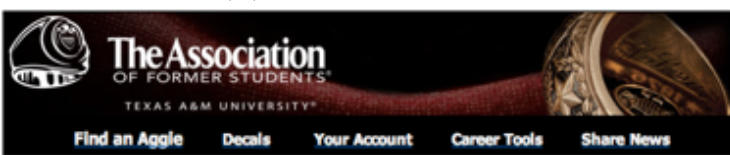

\section{Howdy, Chanee!}

Texas A\&M is unique among public universities for many reasons, most notably for embracing the core values of excellence, integrity, leadership. loyalty, respect, and selfless service. And these core values have led us to become a flagship university in contributing to the betterment of Texas and the nation.

To continue on this course, we need your support. Being a part of the Aggie Network means joining together to make an impact for Texas A\&M. Small gifts make a big difference in the lives of our students, your fellow Aggies. Texas A\&M's impact on the world would not be-and will not be-possible without you.

Your gift to The Association of Former Students' Annual Fund supports scholarships, academic excellence, and student organizations across the university.

Thank you for all that you do to keep Texas A\&M great-and gig 'em!

If you have alroady made your 2013 gift, thank you for your support and promotion of the Aggie Spirit!

In The Aggie Spirit,

Vice President of Marketing and Programs

\section{Make a Gift}

(b) Directed E-mail

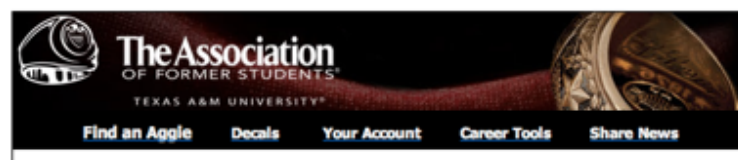

\section{Howdy, Chanee!}

Texas A\&M is unique among public universities for many reasons, most notably for embracing the core values of excellence, integrity, leadership, loyalty, respect, and selfiess service. And these core values have led us to become a flagship university in contributing to the betterment of Texas and the nation.

To continue on this course, we need your support. Being a part of the Aggie Network means joining together to make an impact for Texas A\&M. Small gifts make a big difference in the lives of our students, your fellow Aggies. Texas A\&M's impact on the world would not be-and will not be-possible without you.

Your gift to The Association of Former Students' Annual Fund supports scholarships, academic excellence, and student organizations across the university. You can also choose to direct some or all of your gift specifically to support programs at your academic college.

Thank you for all that you do to keep Texas A\&M great-and gig 'em!

If you have already made your 2013 gift, thank you for your support and promotion of the Aggie Spiriti

In The Aggie Spirit,

Marty Holmes ' 87

Vice President of Marketing and Programs

(9) Make a Gift

E-mails to groups 


\section{Appendix: Web Pages}

The web pages for the electronic donations from the hyperlink in the e-mail had some slight differences made by AFS to make the webpage more "readable": (1) the order of entering the donors name and the gift amount was switched, (2) the control group was giving the option either to make a gift in someone else's name or to donate for missing years. The analysis is unchanged when those donations are excluded. 
(a) Control Donation Web Page

(b) Directed Donation Web Page

Your loyal support is one of the things that makes Texas A\&M such a special place to be. When you ma Your byal support is one of the things that makes Texas A\&M such a special place to be. Your gitt supports gitt to The Association of Former Students you are supporting student scholarships, student organizatiol student scholarships, student organizations, Aggie traditions and so much more. You can choose to direct Aggie traditions and so much more. So make your gift today so that your generosity of spirit will continue your gift to support specifically your academic college, or to the Annual Fund, which supports muttiple

$\begin{array}{ll}\text { set an example for fellow Aggies. } & \text { priorities across the univios } \\ \text { example for fellow Aggios. }\end{array}$

Gift Amount Login to pre-populate form, or create your account tods

Would you llike to make this a recurring gift?

$\checkmark$ This is a payment on a pledge.

Employer Gift Matching

Find your company's matching gift ratio

name and matching ratio below. The bookup Includes instructions for submitting matching

paperwork.

Company

Matching Ratio

[ ] : 0 (i.e. $1: 1$ or $0.5: 1$ )

Your Name

First Name* Last Name* Class Year

Which best describes you?

Former Student

G Graduated in the last 36 months ( $50 \%$ off your Century Club membership).

Address this is where we will mal you receipt, decals, year bars, etc.

Street *

$+2$

Clty *

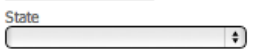

Country

Zlp *

Emall ${ }^{*}$

Phone* Extension Phones Country

Giving Options

Add a Joint Donor + add this

Make This Gift in Someone Else's Name + add this

Include Payment for Missing Year Bars

Is your Century Club Plaque missing something? Include a glit for previous years to get that missing year bar! Minimum gift for each year bar must be at least Bronze level. view levels

+ add year

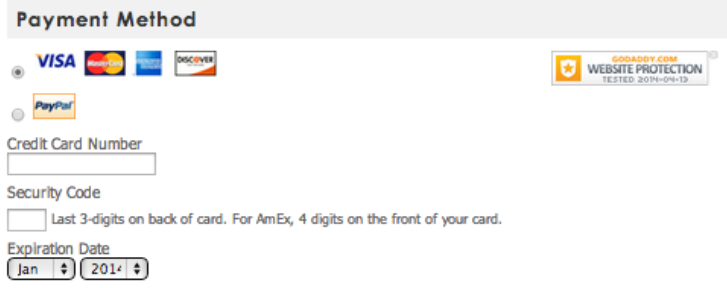

Comments / Special Instruction

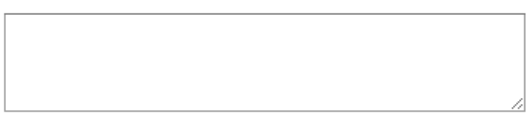

Submit My Cift

\section{Your Name}

First Name* L Last Name*

Which best describes you?

Former Student

Graduated in the last 36 months (50\% off your Century Club membership)

Gift Amount Login to pre-populate form, or create your account today

$\begin{aligned} & \text { Annual Fund Gift Amount } \\ & \$ \square\end{aligned}$
Your gift to The Assoclation of Former Students' Annual Fund supports
scholarshlps, academic excellence, and student organizations across the university

Amount to Your College

Direct a gift specifically to support programs at your academic college

Would you llike to make this a recurring gift?

This is a payment on a pledge.

\section{Gift Matching}

Employer Gift Matching

Find your company's matching gift ratio and multiply the impact of your gift! Then, type their name and matching ratio below. The bookup includes instructions for submiltting matching gift paperwork.

Company

$\begin{array}{ll}\text { Matching Ratio } \\ 0 & 0 \\ 0 & \text { (l.e. } 1: 1 \text { or } 0.5: 1)\end{array}$

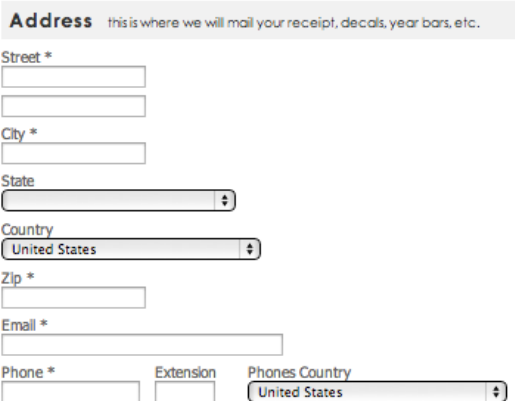

Giving Options

Add a Joint Donor + add this

Payment Method

VISA
Credit Card Number
Security Code
Expiration 3-digts on back of card. For AmEx, 4 digits on the front of your card.

Comments / Special Instruction

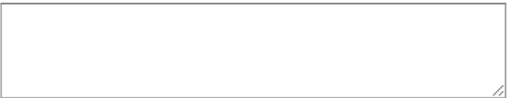

Submit My Cift

14

Web Pages for groups 